\title{
Assessment on the Implementation of Process Approach in Teaching Writing Skill: The Case of Preparatory Schools in Hadiya Zone
}

\author{
Tamirat Hailemariam*, Tsegaye Abie Gebeyehu \\ Department of English Language and Literature, Wachemo University, Hossana, Ethiopia \\ Email address: \\ hailetame21@gmail.com (T. Hailemariam), tsegayeabie@gmail.com (T. A. Gebeyehu), tsegayeA@wcu.edu.et (T. A. Gebeyehu) \\ ${ }^{*}$ Corresponding author
}

\section{To cite this article:}

Tamirat Hailemariam, Tsegaye Abie Gebeyehu. Assessment on the Implementation of Process Approach in Teaching Writing Skill: The Case of Preparatory Schools in Hadiya Zone. Science Journal of Education. Vol. 8, No. 3, 2020, pp. 87-93. doi: 10.11648/j.sjedu.20200803.14

Received: June 16, 2020; Accepted: June 30, 2020; Published: August 5, 2020

\begin{abstract}
The main purpose of this study was to assess the implementation of process approach in writing skills in preparatory schools of Hadiya zone which is found in southern part of Ethiopia 230kms far away from Addis Ababa (the Capital). The subjects of the study were ten (10) English teachers and 500 students of the grade levels. Simple random sampling was used for students and purposive sampling was used for teachers. The data were collected through four instruments; namely written test, questionnaire, classroom observation and document analysis. The data were analyzed using $\mathrm{Z}$ score, achievement test score and descriptive statistics for the written test, simple descriptive statistics for close ended questionnaire and classroom observation and thematic and inductive analysis techniques for open ended questionnaire and document analysis. The findings of this study revealed that most of the teachers and students $(80 \%)$ were not implementing process approach in writing skill due to shortage of time, lack of exposure, low background and lack of interest. Therefore, it was suggested that writing skills should be taught according to its principles in process approach at preparatory schools because they are facing many challenges at college courses, teachers should expose learners for different writing activities and the textbooks should be revisited in line with process approach in writing skills.
\end{abstract}

Keywords: Process Approach, Writing Skills, Implementation

\section{Introduction}

The Communicative Language Teaching (CLT) gives equal chance for all language skills both micro and macro skills. But most students give priority for micro skills especially for grammar. Next to this, they like working on reading and vocabulary sections. Of all skills in English, writing is considered to be the most complex and difficult skill to master. This difficulty, according to Richards and Renandya (2002) lies not only in generating and organizing of ideas but also in translating these ideas into readable texts. Writing is an important skill that should be learned or improved.

In most parts of the world, English is used as a means or medium of communication among a wide range of people. Of course, communication through effective use of language skills is the recent main objective teaching English that the
Communicative Approach requires. The status of English in Ethiopia is that of a foreign language. Students learn the language as a subject and also use it as a medium of instruction for other subjects in high schools, colleges and universities. Thus, in order to make the students successful, the four language skills (speaking, reading, listening, and writing) have to be presented in a meaningful and an integrated manner since Communicative Language Teaching Approach calls for a balanced presentation whereby no means any skill is dominant over the others [10]. Writing is also done for communicating messages and reinforcing other language skills.

Pincas [9] states that writing (composing) is a process which involves arrangement of ideas into sentences, organization of those sentences into paragraphs and then 
construction of whole essays, stories...etc.

Writing is a messy business. Most people progress through a number of untidy drafts before reaching a final version. Nor do they always follow what might seem a national order of priority; it is true that on the whole good writers think about content first and form later, but this order is not consistently observed. Actual content may be altered at quite later stages in the drafting, and changes into sentence or paragraph organization relatively early [12]. Writing is a process which uses purpose and audience framework for any choice of language, idea and organization.

The reasons for teaching writing to the students as a foreign language include reinforcement, language development; learning style and most importantly, writing as a skill on its own right [6]. As a result, it needs giving attention on word selection, punctuation, spelling and grammar in order to write a unified and coherent paragraph or essay or any text. Unity, coherence and adequate development are also necessary.

Effective writing cannot be done in a short time, that is, effective writing needs thinking more to transmit message to the audience. Due to this, every writer should pass through a number of successive steps before the final draft (planning, outlining, drafting and rewriting). Process approach doesn't need only the product or output. But, it needs the procedures that the writer passes through. It is a preferable approach to that of product approach [8]. This research is planned to check the implementation of process approach in writing skills and identify the factors that affect writing skills of Hadiya Zone preparatory School students. A process approach to writing pays attention to the various steps that any piece of writing goes through. By spending time with learners on pre-writing phases, editing, re-drafting and finally publishing the work, the process approach aims to get the heart of various skills that should be employed when writing [7].

Abebe Mengesha [1] conducted a research on "Awareness of Subject Area Instructors about their Contributions to the Development of Students' Writing Skills" and Teshale Lemma [11] "The Relation between Teachers and Students Perception of Writing Skills and Students Academic Achievement", but they didn't see the application of process approach in focus. When the students join university, they were unable to write an effective sentence or paragraph. As a result, most of TEFL teachers of the university were facing problems with students' writing skills. So, this motivated the researchers to conduct this study in Hadiya Zone preparatory schools to check the implementation of process approach in teaching writing skills.

\section{Objectives of the Study}

The primary aim of this study was to assess the implementation of process approach in writing skills. The research specifically aimed at to:

1. Explore the implementation of process approach in teaching writing skills;

2. Find out the challenges that affect the implementation of process approach in teaching writing skills;

3. Describe the magnitude of the challenges so that priorities can be set for immediate decisions

\section{Research Methodology}

Mixed research design was employed in order to conduct this study because it helped the researchers to have a valid data for the study or to gain a better, more substantial picture of the reality and to gain a more sophisticated understanding of the issue on the research questions and its objectives in a natural way. A single case study was applied in this study because the researchers wanted to study the case in detail.

The study was conducted on government preparatory schools in Hadiya Zone-Southern Nations, Nationalities and Peoples Region (SNNPR) in general and preparatory schools in particular. The schools were selected purposively since the sites enabled the researchers to be in the school to make a thorough study. Preparatory schools EFL teachers and students were the target population of this study.

Ten English teachers of the grade level were included as a sample for this study because they were fewer in number and easily manageable. Out of Grade 11 and 12 students of the school, the researchers selected 300 sample students using simple random sampling technique in order to have mixed participants (high, medium and low achievers) for questionnaire because they are too large.

In order to collect data for the study, the following data collecting instruments that will be used to have significant inputs: written test, questionnaire, classroom observation and document analysis.

The following procedures were followed while collecting and analyzing the data. Firstly, standard test was adapted and administered to the students. Secondly, questionnaire was prepared, piloted and administered. Thirdly, classroom observation was conducted in three sections in three rounds. Finally, document analysis was done and the analysis took place accordingly.

\section{Results and Discussion}

\subsection{Students' Written Test Analysis}

First of all, written test was given for the students to know the performance of them. The result of the test is as follows: 
Table 1. Results of Students Written Test.

\begin{tabular}{|c|c|c|c|c|c|}
\hline \multicolumn{6}{|c|}{ Achievement test score } \\
\hline & & Frequency & Percent & Valid Percent & Cumulative Percent \\
\hline \multirow{13}{*}{ Valid } & 4.00 & 45 & 22.5 & 22.6 & 22.6 \\
\hline & 5.00 & 43 & 21.5 & 21.6 & 44.2 \\
\hline & 6.00 & 27 & 13.5 & 13.6 & 57.8 \\
\hline & 7.00 & 29 & 14.5 & 14.6 & 72.4 \\
\hline & 8.00 & 16 & 8.0 & 8.0 & 80.4 \\
\hline & 9.00 & 15 & 7.5 & 7.5 & 87.9 \\
\hline & 10.00 & 5 & 2.5 & 2.5 & 90.5 \\
\hline & 11.00 & 4 & 2.0 & 2.0 & 92.5 \\
\hline & 12.00 & 4 & 2.0 & 2.0 & 94.5 \\
\hline & 13.00 & 3 & 1.5 & 1.5 & 96.0 \\
\hline & 14.00 & 5 & 2.5 & 2.5 & 98.5 \\
\hline & 15.00 & 3 & 1.5 & 1.5 & 100.0 \\
\hline & Total & 199 & 99.5 & 100.0 & \\
\hline Missing & System & 1 & .5 & & \\
\hline Total & & 200 & 100.0 & & \\
\hline
\end{tabular}

This table clearly shows that the students' performance is very poor in writing skill because most of the students (74\%) scored below the average value in the achievement test.

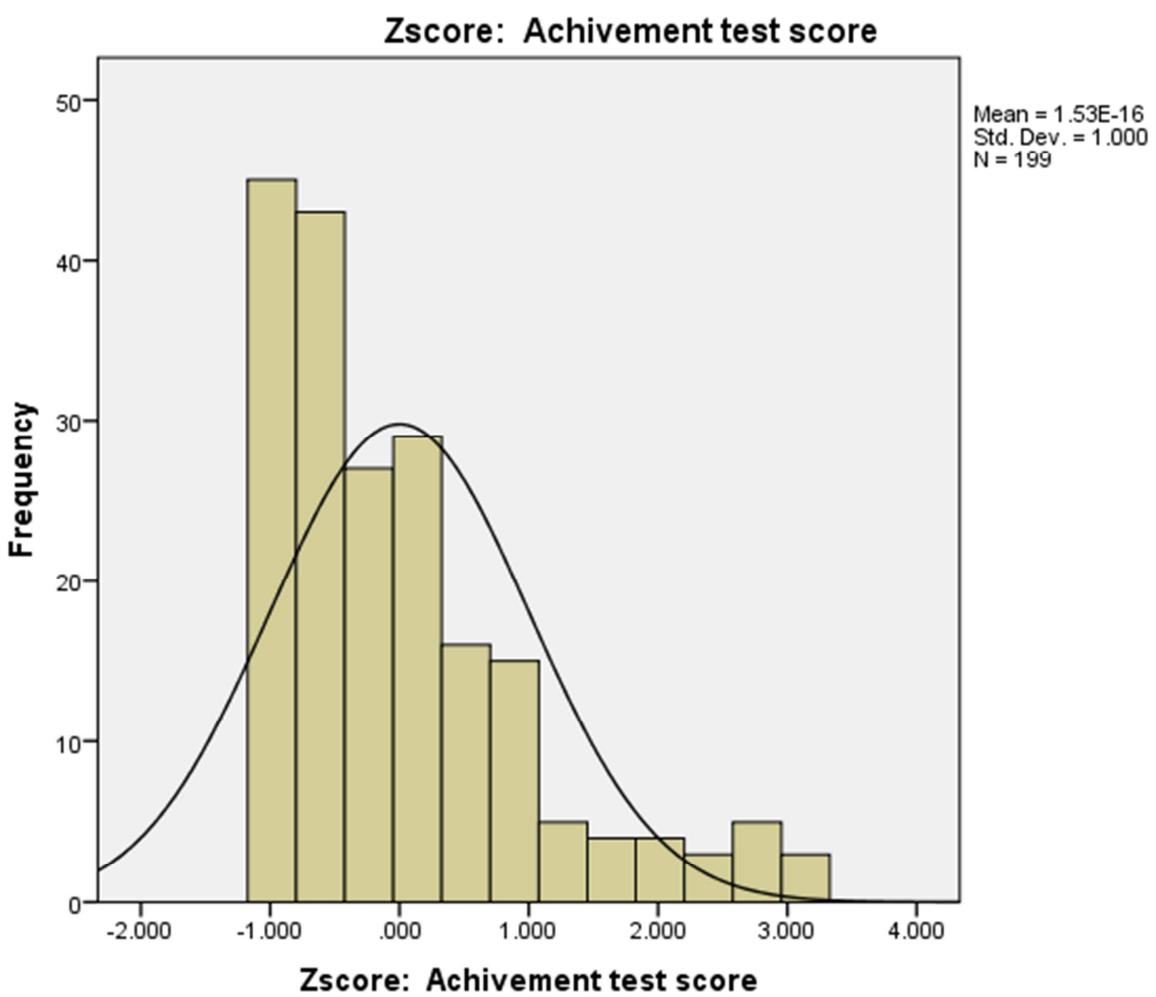

Figure 1. Results of achievement test.

$\mathrm{Z}$ score of the students result also shows that the students were very poor in writing skill because the higher value lies in negative standard deviation and mean or because they perform poor in the test. The results of the students written test illustrates that they need to work hard in writing skill.

Table 2. Analysis of the test results.

\begin{tabular}{llll}
\hline \multicolumn{2}{l}{ Statistics } & & \\
\hline & & Z score: Achievement test score & Achievement test score \\
\hline $\mathrm{N}$ & Valid & 199 & 199 \\
Mean & Missing & 1 & 1 \\
Median & .00000 & 6.6281 \\
Mode & -.23568 & 6.0000 \\
Std. Deviation & -.986 & 4.00 \\
\hline
\end{tabular}


Students who write a paragraph or essay using process approach were very limited. Rather most of the students write haphazardly. As a result, their paragraphs were poor and full of errors. The mean, median, mode and standard deviation clearly illustrates this. If they were using process approach, they would be effective in their composition. It can be generalized that the students failed to write effective paragraph because they were not using process approach.

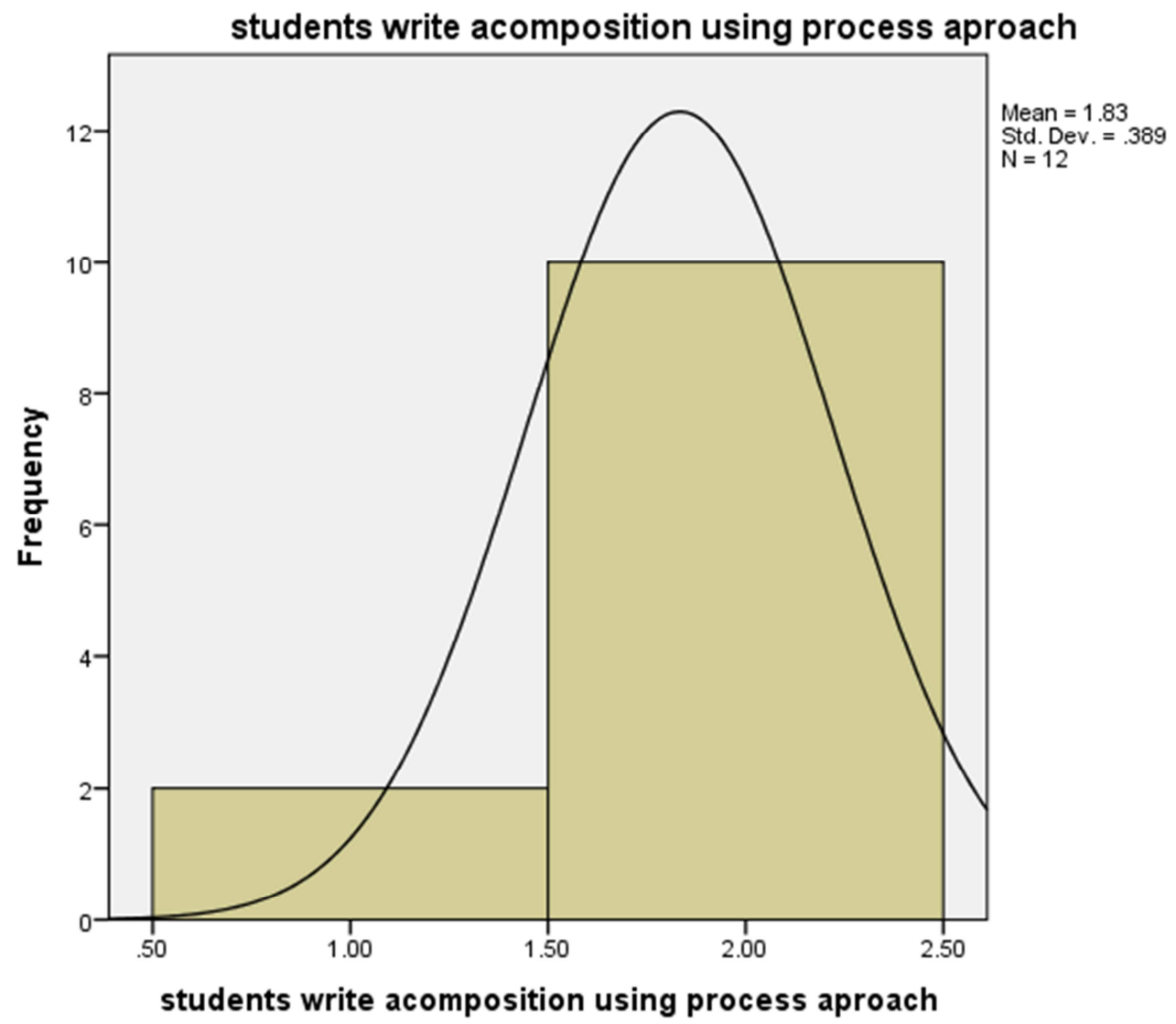

Figure 2. How students compose a paragraph.

As can be seen from the histogram, most of the students fail to write a paragraph using process approach. Thus, most of them scored below the average. They would have improved their writing skills if they had used process approach.

\subsection{Analysis of the Questionnaire}

It was found from the questionnaire that both teachers and students were not actually practicing writing as process approach allows.

Table 3. Students responses regarding writing approaches.

\begin{tabular}{llll}
\hline \multirow{2}{*}{ Item } & \multirow{2}{*}{ Responses } & Respondents & \\
\cline { 3 - 4 } & & Frequency & Percentages (\%) \\
\hline Which of the following approach is better for you to & Process approach & 255 & 85 \\
learn writing skill? & Product approach & 45 & 15 \\
Total & & 300 & 100 \\
\hline
\end{tabular}

As it can be seen from table 3, 255 (85\%) of the students preferred process approach and $45(15 \%)$ of the students responded that process approach was better for them. From this, it can be concluded that process approach is preferable to learn writing skill.

Table 4. Students response on the frequency they learn writing skill.

\begin{tabular}{llll}
\hline \multirow{2}{*}{ Item } & \multirow{2}{*}{ Responses } & Respondents & Percentages (\%) \\
\cline { 3 - 4 } & Usually & Frequency & - \\
How often do you learn writing skill in the & Sometimes & 98 & 32.6 \\
classroom using process approach? & Rarely & 40 & 13.4 \\
& Not at all & 162 & 54 \\
Total & & 300 & 100 \\
\hline
\end{tabular}


From this table, it is possible to see that the students don't learn writing skill usually. 98 (32.6\%) replied that they learn the skill sometimes, $40(13.4 \%)$ said that they learn it rarely and $162(54 \%)$ students replied that they were not learning writing skill at all. Generally, the students were passive in writing skill because they were not exposed to writing exercises.

Table 5. Students response on their interest to write paragraph using process approach.

\begin{tabular}{llll}
\hline \multirow{2}{*}{ Item } & Responses & Respondents \\
\cline { 2 - 4 } & & Frequency & Percentages (\%) \\
Are you voluntary to write a paragraph/composition using & Yes & 105 & 35 \\
process approach? & No & 195 & 65 \\
Total & & 300 & 100 \\
\hline
\end{tabular}

This table vividly illustrates that the students interest to learn writing skill. $105(35 \%)$ responded that they were voluntary to learn but $195(65 \%)$ of the students replied that they were not voluntary to learn writing skill. From this, it can be concluded that most students $(65 \%)$ were not voluntary to learn writing skill. So, they were not good at composing since they dislike or hate the skill.

Table 6. Students responses on the frequency they practice writing outside the classrooms.

\begin{tabular}{|c|c|c|c|}
\hline \multirow{2}{*}{ Item } & \multirow{2}{*}{ Responses } & \multicolumn{2}{|c|}{ Respondents } \\
\hline & & Frequency & Percentages (\%) \\
\hline \multirow{4}{*}{$\begin{array}{l}\text { How often do you practice writing skill } \\
\text { Outside the classroom with process approach? }\end{array}$} & Usually & 7 & 2.3 \\
\hline & Sometimes & 56 & 18.7 \\
\hline & Rarely & 20 & 6.7 \\
\hline & Not at all & 217 & 72.3 \\
\hline Total & & 300 & 100 \\
\hline
\end{tabular}

As the above table shows, $7(2.3 \%)$ students usually practice writing skill outside the class. 56 (18.7\%) students answered that they practice writing skill sometimes and $20(6.7)$ rarely practice writing outside the class. However, nearly $217(72.3 \%)$ students said that they were unluckily to practice writing except the classroom. This implied that most students have problems in writing tasks because they were not exposed to practice it outside the classroom by themselves. If they practice more writing activities at home, they may become active writers in the class.

Not only students but also teachers don't have interest to use process approach while teaching writing skills rather they like to request the students to bring the final product. As a result, they don't follow how the students compose the final paragraph/essay. The factors were the following: shortage of classes, lack of audio-visual materials, lack of textbook, lack of interest, the time given was not enough, lack of vocabulary, lack of developing idea if the topic was not clear, grammar problems and lack of experience from the earlier grades.

\subsection{Analysis of Observation Results Observation on Students' Behavior}

Table 7. Results of classroom Observation (students).

\begin{tabular}{|c|c|c|c|}
\hline \multirow{2}{*}{$\begin{array}{l}\text { Item } \\
\text { The students: }\end{array}$} & \multirow{2}{*}{ Responses } & \multicolumn{2}{|c|}{ Respondents } \\
\hline & & Frequency & Percentage $\%$ \\
\hline \multirow{2}{*}{ write a composition using process approach } & Yes & 2 & 16.7 \\
\hline & No & 10 & 83.3 \\
\hline \multirow{2}{*}{ have background experience in writing exercise } & Yes & 3 & 25 \\
\hline & No & 9 & 75 \\
\hline $\begin{array}{l}\text { have awareness in using cohesive devices (conditioning } \\
\text { conjunctions) }\end{array}$ & Yes & - & - \\
\hline \multirow{2}{*}{ have adequate vocabulary } & Yes & 4 & 33.3 \\
\hline & No & 8 & 66.7 \\
\hline \multirow{2}{*}{ make grammatical mistakes } & Yes & 6 & 50 \\
\hline & No & 6 & 50 \\
\hline \multirow{2}{*}{ give feedback in pairs and groups } & Yes & - & - \\
\hline & No & 12 & 100 \\
\hline \multirow{2}{*}{ write coherent and unified paragraph using process approach } & Yes & - & - \\
\hline & No & 12 & 100 \\
\hline \multirow{2}{*}{ take feedback and make certain correction } & Yes & 12 & 100 \\
\hline & No & - & - \\
\hline
\end{tabular}


As the above table depicts, most of the students $10(83.3 \%)$ were not using process approach to learn writing skill while 2 $(16.7 \%)$ were trying to apply it partially. In addition to this, most students $9(75 \%)$ were not having good background knowledge on writing skill and $3(25 \%)$ were having good background knowledge. All of the students were not using cohesive devices while writing certain composition that made them to be very poor in their writing. Furthermore, some students were having good vocabulary usage but $8(66.7 \%)$ of them were not good vocabulary power to write a paragraph/composition.

In addition, half of the students were making grammatical mistakes in common way but half of them were not doing this. Almost all of the students were not giving feedback in pair/group and their paragraphs/compositions were not coherent and united that can attract the readers but all of them voluntary to take feedback and make certain correction. The following table shows this:

Table 8. Results of classroom Observation (teachers).

\begin{tabular}{|c|c|c|c|}
\hline \multirow{2}{*}{$\begin{array}{l}\text { Item } \\
\text { Teachers: }\end{array}$} & \multirow{2}{*}{ Responses } & \multicolumn{2}{|c|}{ Respondents } \\
\hline & & Frequency & Percentage $\%$ \\
\hline \multirow{2}{*}{ encourage students to write paragraph using process approach } & Yes & - & - \\
\hline & No & 12 & 100 \\
\hline \multirow{2}{*}{ show the steps found in process approach } & Yes & 2 & 16.7 \\
\hline & No & 10 & 83.3 \\
\hline \multirow{2}{*}{ give clear instruction for the lesson } & Yes & 4 & 33.3 \\
\hline & No & 8 & 66.7 \\
\hline \multirow{2}{*}{ give enough time for student to write } & Yes & 4 & 33.3 \\
\hline & No & 8 & 66.7 \\
\hline \multirow{2}{*}{ make the students to participate in pairs and groups } & Yes & 1 & 8.3 \\
\hline & No & 11 & 91.7 \\
\hline \multirow{2}{*}{ give feedback on the students' written work } & Yes & 2 & 16.7 \\
\hline & No & 10 & 83.3 \\
\hline \multirow{2}{*}{ motivate learners to use process approach } & Yes & - & - \\
\hline & No & 12 & 100 \\
\hline bring authentic materials for learners in classroom & No & 12 & 100 \\
\hline
\end{tabular}

As it was observed during study time, the teachers were not teaching writing skill according to its principles. For instance, most of them were not encouraging the students to write using process approach and most of them $(83.3 \%)$ of the teachers were not showing the steps in process approach while the students were writing certain text. To add more, most of them $(66.7 \%)$ of them were not giving clear instruction on how to write and the students were not given enough time to have an effective writing.

It was also observed that the students were not engaged actively in pair/group works to make lesson interactive and lifelong and they were not gaining written feedback on what they wrote. Besides this, the students were not motivated to use process approach while writing outside the classroom and all of the teachers were not using authentic materials while teaching the students in the classroom to make the lesson real-life. Generally, the data from the observation shows that process approach was not applied in preparatory schools of Hadiya zone mostly.

\subsection{Results of Document Analysis}

English textbooks of preparatory level were analyzed. The result showed the following:

The textbooks have some common writing activities and the inputs/sources are previous textbooks designed by MOE. Most of the activities were directly taken from those books and they were not communicative and were not designed in meaningful contexts.
The textbooks are composed of similar writing activities such as paragraph writing, letter writing and summary writing. Preparatory level is a stage where students can master various forms of academic writings but they were restricted to these writings because they were included in the books. Most of them were designed in product approach not process one-they were not as such communicative. In addition, they were not authentic or real-life based and supported by visual aids.

The suggested procedures in the books were not clear which means they don't show what students do in writing skills. Furthermore, they were not interactive that don't encourage pair and group works for the involvements of learners. Besides these, the writing contents listed in the textbooks were not according to the needs of students-they were traditional and unauthentic.

\section{Conclusions and Recommendations}

\subsection{Conclusions}

The following conclusions were drawn:

1. The students of preparatory level were poor in writing skills and most of them were scoring below the average value.

2. The teachers and students of the grade level were not practicing writing skill using process approach-they were not following the stages in process approach.

3. There are some factors which hinder the 
implementation of process approach such as shortage of time, low background and interest, inappropriate contents and lack of support.

4. The textbooks were designed in CLT strategies. As a result, they were not interactive and authentic.

\subsection{Recommendations}

At last, the following recommendations were made:

1. The students should be engaged in different forms of writings so as to be active writers in the real-life.

2. Writing skill should be taught with process approach at this level because it encourages learning

3. Students should practice writing by following the steps in process approach and teachers create the opportunity and motivate learners.

4. The textbooks should be revisited in CLT approach that needs interactive activities and the contents for writing should be based on the needs of learners and updated

\section{References}

[1] Abebe Mengesha. (2004). Awareness of Subject Area Instructors about Their Contributions to the Development of Students' Writing Skills. AA: AAUP (Unpublished thesis).
[2] Atkins, J. etal. (1996). Skills Development Methodology (Part2). A. A: AAUP.

[3] Brown, H. T., (1994). Teaching by Practice: An Interactive Approach to Language Pedagogy $\left(4^{\text {th }} \mathrm{Ed}\right)$. London: Longman.

[4] Byrne, D., (1998). Teaching Writing Skills. London: Longman.

[5] Emory, D., (1995). Improve Your Essay: Form A. New York: Glencoe.

[6] Harmer, J., (1991). The Practice of English Language Teaching I. New York: Longman.

[7] Harmer, J., (2001). The Practice of English Language Teaching II. New York: Longman.

[8] Nunan, D., (1998). Language Teaching Methodology: A Testbook for Teachers. New York: Longman.

[9] Pincas, A., (1982). Teaching English Writing. London: Macmillan.

[10] Stern, H. H., (1982). Fundamental Concepts of Language Teaching. Great Britain: OUP.

[11] Teshale Lemma. (2009). The Relation between Teachers and Students Perception of Writing Skills and Students Academic Achievement. AA: AAUP (Unpublished thesis)

[12] Ur, P. (1996). A Course in Language Teaching: Practice and Theory. Great Britain: CUP. 